УДК 332.142 .4

\title{
В.П. Кобыльников
}

\section{ТЕРРИТОРИАЛЬНОЕ ОБЩЕСТВЕННОЕ САМОУПРАВЛЕНИЕ: РЕСУРС РАЗВИТИЯ}

Исследуется территориальное общественное самоуправление как механизм участия населения в решении вопросов местного значения и социально-экономическом развитии муниципальных образований. В ходе подготовки работы выявлено отсутствие учета актуальной информации о количестве организаций территориального общественного самоуправления в масштабе страны, что не позволяет учитывать их потенциал при планировании развития территорий. Проведен анализ деятельности организаций территориального общественного самоуправления в Вологодской области, обобщена практика реализации проектов инициативного бюджетирования в городах Вологда и Череповец. Автором предпринята попытка обосновать влияние организаций территориального общественного самоуправления на социально-экономические процессы и формирование социального капитала. В связи с этим предложен перечень показателей для оценки деятельности организаций территориального общественного самоуправления. Сформулированы предложения по повышению эффективности работы с организациями территориального общественного самоуправления в регионе, в том числе посредством создания координационной структуры, ресурсных центров и пула консультантов. Отмечается необходимость проведения дальнейших исследований по данной тематике.

Ключевые слова: территориальное общественное самоуправление, социально-экономическое развитие, социальный капитал, инициативное бюджетирование, муниципальное образование, регион.

DOI: $10.35634 / 2412-9593-2019-29-4-441-447$

На современном этапе развития государства вопросы обеспечения устойчивого поступательного социально-экономического развития территорий и повышения качества жизни населения являются взаимосвязанными и одними из приоритетных.

Учитывая необходимость эффективного использования всех имеющихся ресурсов, требуется формирование новой парадигмы социально-экономического развития муниципалитетов, основанной на всемерном гражданском участии.

Такое участие становится ресурсом решения проблем на местах в условиях ограниченных возможностей муниципальных образований [10. С. 150]. Низовая локальная активность является скрытым резервом, мобилизация которого способна придать импульс социально-экономическому развитию [8. С. 89].

По итогам заседания Совета по развитию местного самоуправления 5 августа 2017 г. Президент Российской Федерации В.В. Путин утвердил перечень поручений, в рамках которого органам власти регионов поручено обеспечить широкое привлечение граждан к определению направлений деятельности по благоустройству территорий муниципальных образований и их непосредственное участие в такой деятельности, а также рекомендовано создать условия для развития территориального общественного самоуправления (далее - ТОС) [22].

ТОС зародилось в нашей стране в середине 1990-х гг. [10. С. 157], институционально оформлено в современном его виде с принятием Федерального закона от 6 октября 2003 г. № 131-Ф3 «Об общих принципах организации местного самоуправления в Российской Федерации» [1] (далее - Федеральный закон от 6 октября 2003 г. № 131-Ф3).

Специфика института ТОС определяется его природой: ТОС одновременно выступает как структура гражданского общества, форма территориальной интеграции граждан, элемент системы местного самоуправления [4. С. 110], субъект управления [10. С. 157].

В связи с комплексным характером феномен ТОС является объектом изучения различных дисциплин: истории, социологии, политологии и юриспруденции [10. С. 152]. Однако, по мнению автоpa, существует потенциал исследования ТОС в рамках экономических дисциплин на основе междисциплинарных подходов.

Целью настоящего исследования является изучение влияния ТОС на социально-экономическое развитие муниципальных образований. Для достижения этой цели мы: 1) провели анализ деятельности ТОС в Вологодской области и других регионах страны; 2) разработали показатели оценки деятельности ТОС, характеризующие их вклад в социально-экономическое развитие; 3) сформулировали 
рекомендации по совершенствованию системы ТОС, направленные на повышение эффективности их деятельности.

Федеральный закон от 6 октября 2003 г. № 131-Ф3 определяет ТОС как форму самоорганизации граждан по месту жительства на части территории поселения для самостоятельного и под свою ответственность осуществления собственных инициатив по вопросам местного значения. В названном законе определены следующие функции ТОС:

1) осуществление инициатив граждан, представительство их интересов;

2) осуществление деятельности по благоустройству территории;

3) осуществление хозяйственной деятельности, направленной на удовлетворение социальнобытовых потребностей граждан;

4) внесение в органы местного самоуправления проектов муниципальных правовых актов;

5) аккумулирование средств граждан и местного бюджета для использования их в целях решения вопросов местного значения.

Территориально ТОС может осуществляться в пределах подъезда многоквартирного жилого дома, многоквартирных жилых домов, групп жилых домов, жилых микрорайонов, а также в пределах сельских населенных пунктов, не являющихся поселениями, и иных территорий проживания граждан.

Всего согласно данным Министерства юстиции Российской Федерации (далее - Минюст России), по состоянию на 9 июня 2018 г. ТОС созданы более чем в 5,6 тыс. муниципалитетов на территории 76 регионов. Общее количество созданных ТОС - 30,1 тыс., при этом в качестве юридических лиц зарегистрировано около 2,4 тыс. ТОС (8 \%) [23]. Минюст России осуществляет функции по ведению реестра зарегистрированных некоммерческих организаций [2], поэтому обладает актуальной информацией лишь относительно небольшого числа ТОС. Информация о ТОС, осуществляющих деятельность без регистрации юридического лица, предположительно, получена Минюстом России по запросу в ходе межведомственного взаимодействия. Пробел заключается в том, что такая информация в масштабах регионов и страны никем не аккумулируется и не поддерживается в актуальном состоянии, отсутствует реестровый учет органов ТОС. Поэтому возникают трудности при оценке динамики распространения ТОС в регионах и связанных с этим процессов.

Целесообразно рассмотреть возможность организации учета ТОС в регионах посредством уведомления органом местного самоуправления, принявшим решение о регистрации устава ТОС, территориального органа Минюста России, который обобщает и актуализирует данную информацию. Обладание подробной информацией о деятельности ТОС в регионе и в муниципальных образованиях позволит учитывать их возможности при осуществлении планирования развития территорий.

В Вологодской области создано 69 ТОС (33 - в Вологде [16], 33 - в Череповце, 2 - в Череповецком районе [21], 1 - в Кадуйском районе). Спецификой региона является концентрация организаций ТОС в городских округах, где такие формы взаимодействия населения и органов местного самоуправления наиболее востребованы. Обратимся к их деятельности.

Среди практик ТОС г. Череповца можно отметить следующие: благоустройство и озеленение; создание детских и спортивных объектов; организация мест отдыха; ремонт и содержание автомобильных дорог; создание и реконструкция памятников; организация и проведение мероприятий; разработка проектов развития территории; внесение предложений в органы местного самоуправления с последующим их включением в муниципальные программы.

Особенностью организации взаимодействия органов местного самоуправления с ТОС на территории г. Череповца является опыт реализации с 2014 г. программы «Народный бюджет - ТОС», в рамках которой ТОС выдвигают общественно значимые инициативы по развитию городского пространства. После народного голосования (в 2018 г. проголосовало более 30 тыс. чел.) наиболее востребованные инициативы получают финансирование за счет средств местного бюджета.

Благодаря проекту «Народный бюджет - ТОС», благоустраиваются территории детских садов и школ, парков и скверов, детские площадки, объекты физической культуры и спорта, устанавливаются светофоры. С 2014 по 2017 г. в рамках проекта «Народный бюджет - ТОС» установлено 23 спортивных объекта, 22 детские площадки, благоустроено 17 территорий, на трех - организовано уличное освещение, установлен светофор и искусственная неровность; благоустроено 4 сквера; создано 3 народные дружины; проведено 195 дворовых праздников (более 18 тыс. участников) [20]. В 2018 г. реализовано 27 проектов ТОС [17], благодаря которым обустроено 2 тротуара, 4 места отдыха, 
3 спортивных пришкольных площадки, 8 детских игровых площадок, установлен светофор, хоккейная коробка, создано место для проведения досуга и пр. [19].

В общей сложности на реализацию инициатив ТОС из бюджета г. Череповца с 2015 по 2019 г. выделено 144,45 млн руб.

Показатели проекта «Народный бюджет - ТОС» в г. Череповце

\begin{tabular}{|l|c|c|c|c|c|c|}
\hline & 2014 г. & 2015 г. & 2016 г. & 2017 г. & 2018 г. & 2019 г. \\
\hline Объемы финансирования, млн руб. & 15,0 & 15,0 & 9,9 & 20,0 & 38,05 & 46,5 \\
\hline Количество проектов, ед. & 2 & 7 & 7 & 12 & 27 & $\begin{array}{c}\text { Итоги } \\
\text { не подведень }\end{array}$ \\
\hline Источник: составлено автором. & \multicolumn{79}{|l|}{} \\
\hline
\end{tabular}

Важной составляющей деятельности ТОС и их взаимодействия с органами власти является участие представителей самоуправления в охране общественного порядка.

ТОС содействует коммуникации жителей с сотрудниками правоохранительных органов, доведению до них информации о социально опасных проявлениях, ведут работу по профилактике правонарушений.

Отдельные ТОС формируют добровольные народные дружины, участвующие в охране общественного порядка на своей территории [25].

В рамках деятельности организаций ТОС г. Вологды накоплен опыт организации и проведения спортивных и творческих мероприятий, праздников; осуществления мониторинга соблюдения графика движения городского транспорта; проведения работ по благоустройству и озеленению, строительству и ремонту; информирования органов власти об актуальных проблемах, волнующих население; осуществления общественного контроля; формирования мнения населения; определения приоритетов бюджетных инвестиций; привлечения частных инвесторов в развитие территорий [24].

В 2018 г. в Вологде впервые реализован проект инициативного бюджетирования «Народный бюджет ТОС», предусматривающий определение организациями ТОС наиболее актуальных проблем микрорайона и выделение финансирования за счет средств местного бюджета в 2019 г. на их решение. Бюджет проекта составил 36 млн руб., которые распределятся между 31 ТОС [18] на ремонт дорог и тротуаров, организацию освещения, обустройство пешеходных переходов и ограждений вдоль дорог, установку и ремонт остановочных комплексов, создание детских и спортивных площадок.

Несмотря на возрастающую роль института ТОС возникает закономерный вопрос об оценке вклада организаций по месту жительства в социально-экономическое развитие муниципальных образований.

Действительно, провести такую оценку ТОС довольно сложно, особенно в контексте недостатка информации о них, а также в силу отсутствия статуса юридического лица у многих организаций. Однако при определенных обстоятельствах произвести соответствующие количественные подсчеты все-таки представляется возможным. Л.И. Полищук и И.Л. Шагалова отмечают, что при финансировании проектов ТОС за счет средств местного бюджета имеет место эффект мультипликатора: в 2009-2011 г. на поддержку проектов ТОС г. Кирова из местного бюджета выделено 10 млн руб., при этом объем частных инвестиций - 15,3 млн руб. [13]. Такой подход допустимо называть мультипликативным, при котором бюджетные средства, выделенные на поддержку деятельности ТОС, привлекают на аналогичные цели внебюджетные ресурсы.

В концепции «РазвитиЕ ТОС в Архангельской области до 2020 г.» приводятся данные, что за период реализации программы поддержки проектов ТОС им были предоставлены субсидии из регионального бюджета в размере 65,3 млн руб., из местных бюджетов - 38,3 млн руб. В то же время сами ТОС привлекли на реализацию проектов 120 млн руб. [3].

Это подтверждается и примерами из практики. Так, ТОС «Городище - наш дом» в 2016 г. инициировал строительство дороги к одноименной деревне в Череповецком районе Вологодской области стоимостью 20 млн руб. (9 млн руб. - бюджетные средства, 11 млн руб. - привлеченные ТОС внебюджетные ресурсы) [6. С. 12].

Мультипликатор является показательным с позиции оценки эффективности деятельности конкретного ТОС, а также организаций муниципального образования или региона. Он демонстрирует 
доверие населения и бизнес-структур к ТОС, а также их способность аккумулировать и расходовать денежные средства.

Помимо привлечения финансовых ресурсов оценить деятельность ТОС возможно через показатель вовлечения населения в проводимые мероприятия по благоустройству, созданию и ремонту объектов локальной инфраструктуры, в организацию и проведение событийных мероприятий. Данный показатель предлагаем агрегировать под термином «личное трудовое участие в деятельности ТОС», единица измерения - «трудочас» - время, затраченное одним человеком на осуществление безвозмездной трудовой деятельности. Если принять во внимание условную стоимость одного часа работы специалиста соответствующего профиля, то любое личное трудовое участие жителей в деятельности ТОС может получить оценку в денежном выражении.

К примеру, активисты ТОС «Солнечный» в г. Череповце провели субботник с участием 60 человек [26]. Среднее время субботника - 2 часа. Один час труда разнорабочего на рынке услуг оплачивается в размере 250 руб. При проведении такого мероприятия по благоустройству силами аналогичного количества наемных работников затраты составят 30 тыс. руб. $(60 \times 2 \times 250)$. В г. Вологде в мероприятии ТОС по уборке Ковыринского парка приняли участие 150 человек [15], его экономический эффект равняется 75 тыс. руб. Если принять во внимание, что мероприятия ТОС проводят и в формате общегородских (с тысячами участников) и не ограничиваются проведением субботников, то рассчитываемый эффект исчисляется миллионами рублей. При таком подходе личное трудовое участие жителей в деятельности ТОС может быть отнесено к нефинансовым инвестициям граждан в преобразование среды проживания.

Деятельность ТОС может быть оценена через показатель оказания органами ТОС услуг населению, который характеризуется как количество граждан, принявших участие в культурно-массовых, детских, спортивных и иных мероприятиях ТОС. Получить представление о качестве оказываемых ТОС услуг возможно посредством опроса жителей.

Для сельских территорий характерен вклад ТОС в стимулирование социально-экономической активности, занятости населения (преимущественно среди старшего и среднего поколения) и мотивации к активной социальной роли в местном сообществе [3].

Помимо экономически осязаемого результата организации ТОС вносят вклад в формирование социального капитала (один из факторов развития наряду с традиционными. - B.К.). Л.И. Полищук характеризует социальный капитал как общественный ресурс, благоприятствующий инвестициям и торговле, способствующий решению общественных проблем, распространению информации и позитивных моделей поведения, укреплению доверия, мобилизации ресурсов для общественных инициатив. Социальный капитал выражается в способности сообществ к коллективным действиям ради достижения общей цели [12. С. 47].

ТОС рассматриваются в качестве инструмента приумножения социального капитала, имеющего на локальном уровне тесную связь с человеческим капиталом, присущим отдельным индивидам [7]. Особенно это проявляется при проведении обучающих мероприятий для активистов ТОС по вопросам ЖКХ, правовой грамотности, общественного контроля, по результатам которых, получив соответствующие знания, граждане влияют на работу управляющих компаний, городских служб, подрядных организаций.

Рост социального капитала выражается в возрастании гражданской активности, распространении практик самоуправления, снижении социальной напряженности [9. С. 67], количества правонарушений, а также формировании эффективного механизма управления в политической и экономической сфере [14. С. 144], основанного на учете мнения населения.

Подводя итоги, следует отметить, что за более чем 20-летний период своего становления ТОС стали неотъемлемым элементом архитектуры гражданского общества муниципального образования, вовлеченными в процессы его развития.

Однако создание организаций ТОС происходит неравномерно как в масштабах страны, так и в разрезе отдельных регионов. Лишь менее $10 \%$ ТОС регистрируются в качестве некоммерческих организаций. Формирование прочной ресурсной базы ТОС без статуса юридического лица практически невозможно и находится за пределами правовой регламентации. В связи с этим видится логичным предусмотреть в федеральном законодательстве нормы, стимулирующие регистрацию ТОС в качестве юридических лиц, а также упростить данную процедуру. 
Вклад ТОС в социально-экономическое развитие муниципального образования бесспорен и заключается в: привлечении финансовых и личных трудовых ресурсов жителей для решения вопросов местного значения, оказании услуг населению, поддержке социально незащищенных категорий граждан, обеспечении правопорядка и приумножении социального капитала.

Перспективным для дальнейшего изучения представляется оценка вклада ТОС в социальноэкономическое развитие муниципальных образований. По результатам данного исследования автором предложено использовать при оценке деятельности ТОС следующие показатели:

- объем финансовых ресурсов, привлекаемых ТОС для осуществления своей деятельности; TOC;

- соотношение бюджетных и внебюджетных ресурсов, привлеченных для реализации проектов

- количество граждан-получателей услуг ТОС;

- личное трудовое участие в деятельности ТОС;

- количество проведенных мероприятий и реализованных проектов ТОС;

- динамика правонарушений на территории деятельности ТОС.

Одним из ключевых факторов развития движения ТОС является ориентированность органов местного самоуправления на взаимодействие с ними.

Органы местного самоуправления не всегда осознают открывающиеся возможности от сотрудничества с ТОС (создание новых социальных технологий, моделей социального партнерства и улучшения качества жизни населения), что препятствует продуктивному участию граждан в решении вопросов местного значения [5. С. 21]. Всесторонняя поддержка инициатив ТОС является гарантией успешного развития территориального самоуправления [11. С. 177]. В связи с этим существует потребность координации развития системы ТОС на региональном уровне. Механизм координации создание ассоциации ТОС (например, Ульяновская область) или регионального совета ТОС (например, Воронежская область). Создание региональной ассоциации ТОС, по мнению автора, более приемлемая модель, поскольку на ее площадке возможно организовать региональный ресурсный центр, аккумулирующий и транслирующий лучшие практики деятельности ТОС, а также способствующий формированию компетенций активных граждан.

Для эффективного функционирования ТОС необходимо создавать на местах доступную инфраструктуру их поддержки посредством формирования сети ресурсных центров (на базе ресурсных центров поддержки некоммерческих организаций) и пула консультантов из числа сотрудников органов местного самоуправления, а также представителей экспертного и научного сообщества.

По мнению автора, в качестве фактора, стимулирующего развитие ТОС, целесообразно предусмотреть меры поддержки их инициатив на региональном уровне либо на уровне муниципальных районов и городских округов.

ТОС аккумулируют значительный потенциал, который, однако, не всегда учитывается органами власти при планировании развития территорий, что препятствует формированию адекватной оценки феномена территориального самоуправления и созданию всеобъемлющих условий для вовлечения ТОС в процессы социально-экономического развития.

Для того чтобы ТОС смогли войти в повестку развития в национальном масштабе, необходимо организовать учет всех ТОС в стране (в том числе незарегистрированных в качестве юридических лиц), а также информации об их деятельности. Для этого целесообразно организовать взаимодействие органов местного самоуправления и территориального органа Минюста России посредством уведомления последнего о создании ТОС и предоставления ежегодной информации.

Движение территориального общественного самоуправления в ближайшее время продолжит расширяться количественно и качественно. А при должной поддержке официальных институтов гражданское участие в формате ТОС способно стать одним из драйверов развития местных территорий и ключевым механизмом участия населения в решении вопросов местного значения.

\section{СПИСОК ЛИТЕРАТУРЫ}

1. Федеральный закон от 6 октября 2003 г. № 131-Ф3 «Об общих принципах организации местного самоуправления в Российской Федерации» // Собрание законодательства Российской Федерации. 2003. № 40. Ст. 3822.

2. Указ Президента РФ от 13 октября 2004 года № 1313 «Вопросы Министерства юстиции Российской Федерации» // Собрание законодательства Российской Федерации. 2004. № 42. Ст. 4108. 
3. Постановление Правительства Архангельской области от 22 июля 2014 года № 291-пп «Об утверждении концепции развития территориального общественного самоуправления в Архангельской области до 2020 года». URL: http://base.garant.ru/25116390/

4. Баженова О.И. Правовая природа территориального общественного самоуправления // Местное право. 2016. № 1. С. 109-110.

5. Забелина Е.П. О научной концепции территориального общественного самоуправления // Территориальное общественное самоуправление в малых городах и сельских поселениях и его взаимодействие с органами местного самоуправления: сб. материалов общерос. науч.-практ. конф. Москва, 9 июня 2017 г. М.: ИТД «ПЕРСПЕКТИВА», 2017. $174 \mathrm{c}$.

6. Кидяев В.Б. О потенциале территориального общественного самоуправления // Территориальное общественное самоуправление в малых городах и сельских поселениях и его взаимодействие с органами местного самоуправления: сб. материалов общерос. науч.-практ. конф. Москва, 9 июня 2017 г. М.: ИТД «ПЕРСПЕКТИВА», 2017. $174 \mathrm{c}$.

7. Лагунова С.В. Институционализация территориального общественного самоуправления в локальной среде (на примере Архангельской области). URL: http://emsu.ru/face/dissert/avtoreferat_lagunovasv.pdf.

8. Лепустин В.Е. Мельцер М.М. Гражданская активность - скрытый резерв развития региона // Территориальное общественное самоуправление в малых городах и сельских поселениях и его взаимодействие с органами местного самоуправления: сб. материалов общерос. науч.-практ. конф. Москва, 9 июня 2017 г. М.: ИТД «ПЕРСПЕКТИВА», 2017. $174 \mathrm{c}$.

9. Максимов В.П. Оценка эффективности территориального общественного самоуправления и его вклада в социально-экономическое развитие муниципального образования // Вестн. Челябинского гос. ун-та. 2004 . № 1. С. 63-75.

10. Мерсиянова И.В. Территориальное общественное самоуправление как форма общественного участия // Вопр. государственного и муниципального управления. 2010. № 3. С. 149-168.

11. Овчаренко Р.К. Территориальное общественное самоуправление в системе местного самоуправления России // Государственное и муниципальное управление. Уч. зап. 2017. № 4. С. 176-180.

12. Полищук Л.И., Меняшев Р.Ш. Экономическое значение социального капитала // Вопр. экономики. 2011. № 12. С. 46-65.

13. Полищук Л.И., Шагалов И.Л. Территориальное общественное самоуправление: предпосылки, функции, оценка. URL: https:/grans.hse.ru/data/2016/04/22/1130204445/N-09.1\%20\%D0\%A8\%D0\%B0\%D0\%B3 \%D0\%B $0 \% \mathrm{D} 0 \% \mathrm{BB} \% \mathrm{D} 0 \% \mathrm{BE} \% \mathrm{D} 0 \% \mathrm{~B} 2 . \mathrm{pdf}$

14. Шагалов И.Л. Особенности влияния социального капитала по месту объединений, по месту жительства на городское развитие // Журнал Новой экономической ассоциации. № 2 (22). С.133-151.

15. Активисты ТОСов в разных районах Вологды присоединились к субботнику. URL: https://вологда.pф/ news/society/9954/.

16. Границы двух новых ТОСов определены в Вологде. URL: https:/вологда.pф/news/society/28214/.

17. В Череповце существенно увеличили «народный бюджет». URL: https://www.gorodche.ru/news/society/ $117055 /$.

18. Дан старт проекту «Народный бюджет TOC». URL: https://www.vologdazso .ru/events/159309/.

19. Народный бюджет. URL: https://mayor.cherinfo.ru/nb.

20. Народный бюджет-TOC. URL: https://duma.cherinfo.ru/duma/94754-narodnyj-budzet-tos.

21. Официальный сайт Администрации Череповецкого муниципального района. URL: https://cherra.ru/.

22. Перечень поручений по итогам заседания Совета по развитию местного самоуправления. URL: http://www.kremlin.ru/acts/assignments/orders/55571.

23. Решение Совета по местному самоуправлению при Совете Федерации на тему «Актуальные вопросы развития территориального общественного самоуправления» от 10 июля 2018 года. URL: http://council.gov.ru/ media/files/sz2XdG cXMk1ytYstAaEqJ7UK4AAq3jSp.pdf

24. Территориальное общественное самоуправление. URL: http://vologda-porta 1.ru/oficialnaya_vologda/index.php ?SECTION_ID $=5434$

25. У ТОСов будут свои дружины. URL: http://35media.ru/articles/2018/07/23/u-tosov-budut-svoi-druzhiny.

26. Члены территориального общественного самоуправления собрали 40 мешков листьев во время субботника в Череповце. URL: https:/cherinfo.ru/news/76424-cleny-territorialnogo-obsestvennogo-samoupravlenia-sobral i-40meskov-listev-vo-vrema-subbotnika-v-cerepovce

Кобыльников Виталий Павлович, аспирант

ФГБУН «Вологодский научный центр Российской академии наук»

160014, Россия, г. Вологда, ул. Горького, д. 56а

E-mail: kobilnikov.v@yandex.ru 


\section{V.P. Kobyl'nikov}

\section{TERRITORIAL PUBLIC SELF-GOVERNMENT: RESOURCE FOR DEVELOPMENT}

DOI: $10.35634 / 2412-9593-2019-29-4-441-447$

The article is devoted to territorial public self-government as a mechanism of public participation in solving local issues and socio-economic development of municipalities. The study reveals a lack of relevant information on the number of organizations of territorial public self-government in the country. This does not allow to take into account their potential during planning the development of territories. The author analyzed the activities of organizations of territorial public self-government in the Vologda region, summarized the practice of initiative budgeting in Vologda and Cherepovets. The researcher attempted to explain the influence of organizations of territorial public self-government on socioeconomic processes and the creation of social capital. In this connection, a list of indicators for assessing activities of organizations of territorial public self-government has been proposed. It is necessary to improve the efficiency of work with organizations of territorial public self-government in the region including through the creation of a coordination structure, resource centers and a pool of consultants. There is a need for further research on this topic.

Keywords: territorial public self-government, social and economic development, social capital, initiative budgeting, municipality, region.

Kobyl'nikov V.P., postgraduate student

Vologda Research Center of the Russian Academy of Sciences

Gor'kogo st., 56A Vologda, Russia, 160014

E-mail: kobilnikov.v@yandex.ru 